short-acting contraceptive methods, with inadequate counselling and barriers in the health care system being contributory factors in such contraceptive failure.

Participant knowledge of sterilisation was greater than that regarding IUDs in this study, probably owing to the presence of sterilisation services in the Western Cape and the lack of IUD promotion and use. The Association for Voluntary Sterilization South Africa (AVSSA), a non-profit organisation, has offered sterilisation services at health care facilities in the Western Cape for many years, including education and awareness campaigns.

The survey results raise questions as to whether the full range of contraceptive methods are available and promoted in all services targeting pregnant and postpartum women, including HIV-positive women. They also suggest that recommended education and counselling regarding healthy timing and spacing of children may be overlooked in health services serving pregnant and postpartum women. High rates of unplanned pregnancy are likely to continue without effective planning between a woman and her partner regarding family size, spacing of children and the selection of wellsuited contraceptive methods that are supported by family planning service providers at health care facilities.

Choice is essential in providing the optimal family planning method to a client. Women in the communities studied have insufficient knowledge about safe, effective and long-acting contraceptive options and therefore are unable to make a fully informed method choice. To provide family planning clients with a choice of contraceptive methods, providers must be adequately trained and equipped to provide counsel about, and offer the full range of, methods available in the public health care sector. Family planning should be appropriate and well-suited to the individual's health and fertility desires. Given their superior effectiveness rates among typical users, long-acting and permanent methods are excellent options for clients who have achieved their desired family size or for those who have recently given birth and wish to plan future pregnancies, and such methods should therefore be promoted and available to clients as part of comprehensive family planning services.

\section{References}

1. Cleland J, Bernstein S, Ezeh A, Faundes A, Glasier A, Innis J. Family planning: the unfinished agenda, Lancet 2006; 368: 1810-1827.

2. Halperin DT, Stover J, Reynolds H. Benefits and costs of expanding access to family planning programs to women living with HIV. AIDS 2009; 23 (suppl 1): S123-S130.

3. Department of Health. Demographic and Health Survery 2003, Preliminary Report. Pretoria: Department of Health, 2004. http://www.doh.gov.za (accessed 20 January 2010).

4. World Health Organization. Improving Access to Quality Care in Family Planning: Medical Eligibility Criteria for Contraceptive Use. 3rd ed. Geneva: World Health Organization, 2004

5. Thonneau P, Almont T. Contraceptive efficacy of intrauterine devices. Am J Obstet Gynecol 2008; 198(3): 248-253.

6. Baumgartner JN, Morroni C, Mlobeli RD, et al. Timeliness of contraceptive reinjections in South Africa and its relation to unintentional discontinuation. Int Fam Plan Perspect 2007; 33(2): 66-74.

Accepted 3 March 2010

\title{
New fly species causing human myiasis identified in Eastern Cape, South Africa
}

\author{
S K Kuria, H J C Kingu, S D Vasaikar, J N Mkhize, J M Iisa, A Dhaffala
}

To the Editor: Myiasis is the infestation of tissues of live vertebrates (humans and/or animals) by dipterous larvae. Human myiasis is classified according to the type of larva producing the lesion, location

Department of Biological Sciences, Walter Sisulu University, Mthatha, E Cape $S$ K Kuria, $\mathrm{PhD}$

J N Mkhize, PhD

J M Iisa, BVetMed

Department of Surgery, Walter Sisulu University

H J C Kingu, MD, MMed (Surg)

A Dhaffala, MB ChB, MMed (Surg)

Department of Medical Microbiology, Walter Sisulu University

S D Vasaikar, MD (Med Microbiol), MB BS and clinical signs. ${ }^{1}$ Myiases in humans are thought to have originated from the close association between humans and domestic animals in ancient times. ${ }^{2}$ Flies that cause myiasis are grouped into three families: Calliphoridae (blowflies), Sarcophagidae (flesh flies) and Oestridae (bot flies). ${ }^{2}$ For a long period species of Sarcophaga have been implicated in myiasis in man and animals. ${ }^{3}$ Other dipterans have also been implicated with causing myiasis in humans, including Cochliomyia hominivorax (Coquerel), ${ }^{1}$ C. macellaria Fab., Phormia regina Meig., Lucilia sericata Meig., L. illustris Meig., Calliphora erythrocephala Meig. and Cynomyia cadaverina Desv. ${ }^{4}$ Nevertheless, several species of flies have been used for maggot debridement therapy (MDT), the commonest being L. sericata Meigen, a greenbottle blowfly which is closely related to the greenbottle $L$. cuprina Wiedmann; however, $L$. cuprina feeds on live as well as necrotic tissue, which is undesirable in MDT. ${ }^{5}$

We aimed to elucidate the fly species that cause myiasis in humans in the Eastern Cape province, South Africa. We collected maggots from necrotic human wounds in patients attending Nelson Mandela Academic Hospital (NMAH) and other clinics within the O R Tambo municipality. These maggots were allowed to grow and pupate, and the emerging flies were subsequently identified. ${ }^{6}$ 


\section{Materials, methods and results}

NMAH is one of the three provincial and tertiary Eastern Cape academic hospitals. It undertakes teaching and research for undergraduate and postgraduate students in the Faculty of Health Sciences at Walter Sisulu University. It offers secondary and tertiary medical services in the former Transkei region of the Eastern Cape province. Maggots were harvested from a full-thickness burn wound in a patient (aged 22 years) from Maclear (Fig. 1) and a dry-gangrene foot of a 57-year-old patient from Slovo Park suburb, Mthatha. The maggots were bred in plastic containers in the laboratory using chicken liver until they pupated. The emerging flies were later identified to species level. The fly species that emerged from maggots harvested from the patient from Maclear were identified as Sarcophaga (Liosarcophaga) nodosa Engel (Fig. 2), while those harvested from the other patient belonged to L. cuprina (Fig. 3).

\section{Discussion}

Myiasis is the infestation of human or animal tissue by larvae of dipteran flies. It is commonly reported in Mexico and South and Central America, ${ }^{7}$ but there is minimal information on myiasis in South Africa. Many species of Calliphoridae are saprophages that feed on animal carcasses, whereas others are obligate parasites. ${ }^{2} S$. (Liosarcophaga) nodosa Engel is a widespread and common species that breeds in carrion and dead arthropods, and in 1972 there was no clear answer about whether it could cause myiasis, either in humans

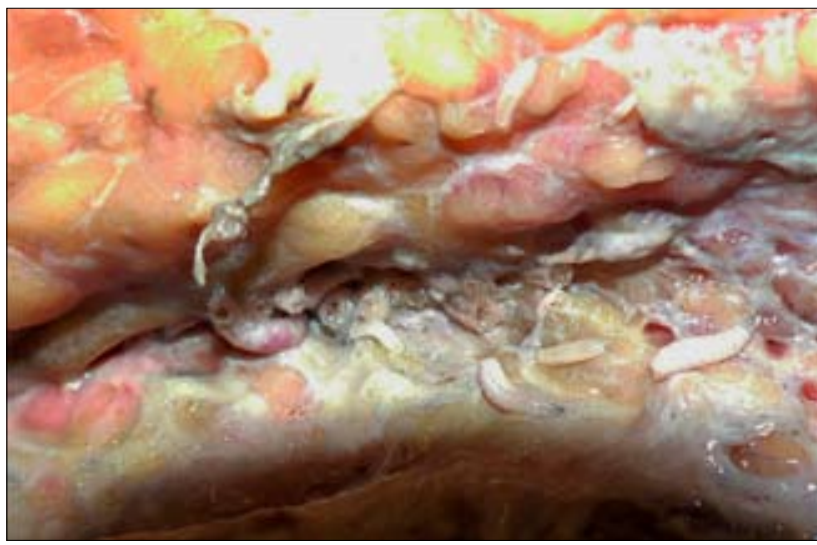

Fig. 1. Wound presented by a patient from Maclear showing maggots (photograph H Kingu).

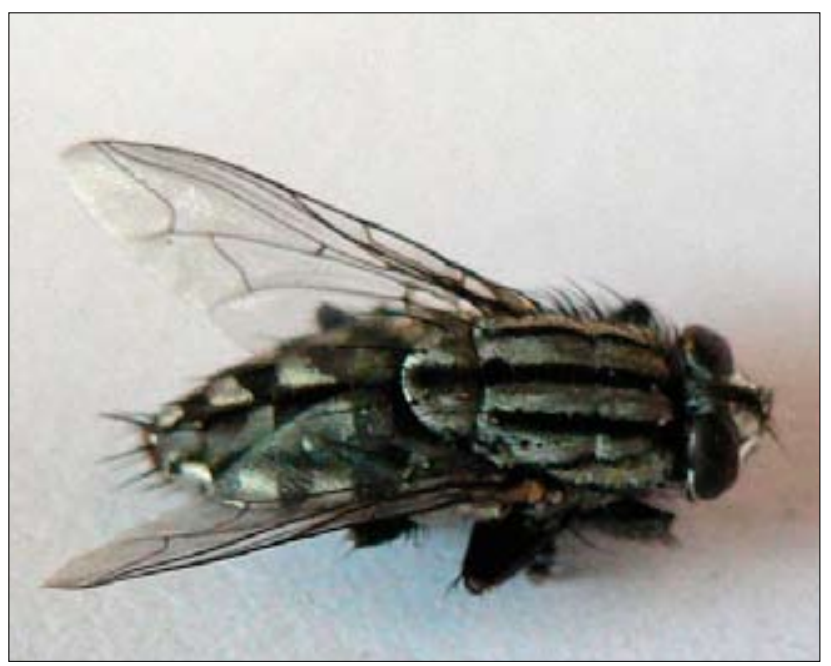

Fig. 2. Sarcophaga (Liosarcophaga) nodosa Engel (photograph H Kingu).

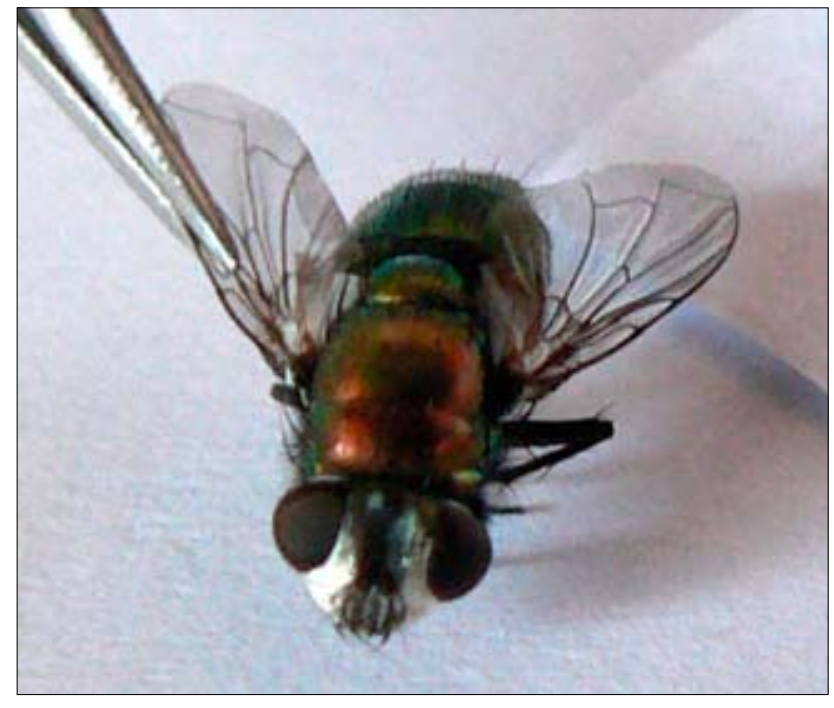

Fig. 3. Lucilia cuprina Wiedmann (photograph H Kingu).

or even in other animals. ${ }^{6}$ This is the first time this species has been recorded as causing myiasis in humans. It is possible that there may be many more fly species that can cause myiasis in humans that are still not known. Flies that emerged from maggots collected from the second patient from Slovo Park, Mthatha belong to L. cuprina (Fig. 3). The research project to determine other fly species associated with human wounds in this region is still ongoing.

We thank M Villet from Rhodes University for identifying the fly specimens, and A Gova who worked tirelessly to ensure that the maggots survived in the laboratory. We also appreciate the assistance of $S$ Swanepoel in editing the photos. This project was supported by a research grant from Walter Sisulu University through the Research Directorate.

\section{References}

1. Duro EA, Mariluis JC, Mulieri PR. Perinatal/neonatal case presentation: umbilical myiasis in a human newborn. J Perinatol 2007; 27: 250-251.

2. Stevens JR, Wallman JF, Otranto D, Wall R, Papes T. The evolution of myiasis in humans and other animals in the Old and New Worlds (part 11): biological and life-history studies. Trends Parasitol 2006; 22: 181-188.

3. Knipling EF. A comparative study of the first-instar larvae of the genus Sarcophaga (Calliphoridae, Diptera), with notes on the biology. J Parasitol 1936; 22: 417-454.

4. Knipling EF, Rainwater HT. Species and incidence of dipterous larvae concerned in wound myiasis. J Parasitol 1937; 23: 451-455.

5. Williams KA, Cronje FJ, Avenant L, Villet MH. Identifying flies used for maggot debridement therapy. S Afr Med J 2008; 98: 630-631.

6. Zumpt F. Calliphoridae (Diptera, Cyclorrhapha). Part IV. Sarcophaginae. Exploration du Parc National des Virunga, Mission de Witte 1933-1935. 1972; 101: 1-264.

7. Çetinkaya M, Özkan H, Köksal N, Coşkun ŞZ, Hacımustafaoğlu M, Girişgin O. Neonatal myiasis: a case report. Turk J Pediatr 2008; 50: 581-584.

Accepted 14 June 2010. 